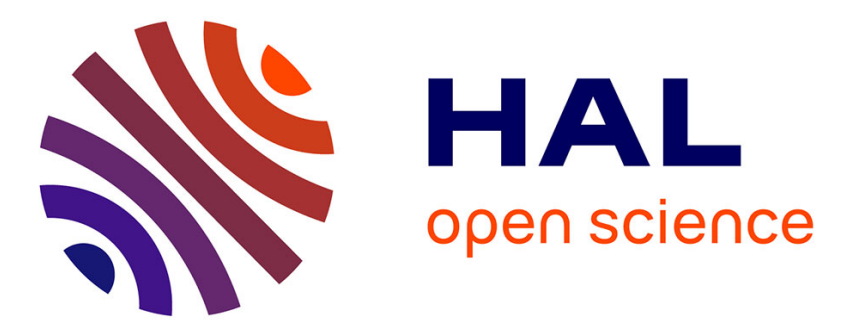

\title{
Two-dimensional modeling of shaft precessional motions induced by blade/casing unilateral contact in aircraft engines
}

Nicolas Salvat, Alain Batailly, Mathias Legrand

\section{- To cite this version:}

Nicolas Salvat, Alain Batailly, Mathias Legrand. Two-dimensional modeling of shaft precessional motions induced by blade/casing unilateral contact in aircraft engines. Turbo Expo, ASME, Jun 2014, Dusseldorf, Germany. 10.1115/GT2014-25688 · hal-01090671v2

\section{HAL Id: hal-01090671 \\ https://hal.science/hal-01090671v2}

Submitted on 18 Jan 2015

HAL is a multi-disciplinary open access archive for the deposit and dissemination of scientific research documents, whether they are published or not. The documents may come from teaching and research institutions in France or abroad, or from public or private research centers.
L'archive ouverte pluridisciplinaire HAL, est destinée au dépôt et à la diffusion de documents scientifiques de niveau recherche, publiés ou non, émanant des établissements d'enseignement et de recherche français ou étrangers, des laboratoires publics ou privés.

\section{(ㅇ)(1) 80}

Distributed under a Creative Commons Attribution - NonCommercial - ShareAlikel 4.0 


\title{
Two-dimensional modeling of shaft precessional motions induced by blade/casing unilateral contact in aircraft engines
}

\author{
Nicolas Salvat*, Alain Batailly, Mathias Legrand
}

\begin{abstract}
In the present work, the focus is made on the occurrence of precessional motions of the shaft—whirling motions-in bladed-disk assemblies, initiated by direct blade/casing contacts in one stage of an aircraft engine. These contact events are favored by increasingly reduced blade-tip clearances and are expected to occur during standard operating conditions. However, it has been shown that potentially harmful interactions may arise and threaten the engine structural integrity.

A 2D in-plane model of an aircraft engine fan stage is built with a set of curved beams for the casing and an assembly straight beams for the bladed-disk. The flexibility of the shaft is reflected by two linear springs attached to the center node of the disk. Contact is initiated through a prescribed casing distortion and the two structures are then left free to interact. Equations of motion are solved via explicit time-marching and contact forces are computed with Lagrange multipliers method allowing to fully satisfy non-penetration conditions. Friction is accounted for through a Coulomb law and permanent sliding is assumed.

Three types of regimes are identified, namely: (1) damped, (2) sustained, (3) divergent, and both forward and backward shaft precessional motions are witnessed. It is shown that the vibratory response of the bladed-disk mainly lies on the first nodal diameter of the first family of modes regardless of the rotational velocity or the type of regime detected. The risk of failure arising from these contact events is highlighted, in particular in the presence of forward whirl, and the need for accurate predictive tools in early design phases of the engine is emphasized.
\end{abstract}

\section{Keywords}

Nonlinear dynamics, numerical contact mechanics, whirl, rotor/stator interactions, vibrations.

\section{Modélisation planaire des mouvements de tournoiement dans les moteurs d'avion induits par des contacts directs aube/carter}

\author{
Nicolas Salvat ${ }^{\star}$, Alain Batailly, Mathias Legrand
}

\section{Résumé}

Cette étude concerne l'apparition de mouvements de précession de l'arbre d'une roue aubagée d'un moteur d'avion — mouvements dits de tournoiement — qui sont initiés par des contacts directs entre sommets d'aubes et carter environnant. Ces événements de contact sont favorisés par des jeux fonctionnels de plus en plus réduits et sont considerés comme acceptables lors des conditions normales d'exploitation du moteur. Cependant, il a été montré par des études numériques et expérimentales que des interactions potentiellement dangereuses peuvent survenir et ainsi menacer son intégrité structurelle.

Un modèle planaire de l'étage de la soufflante est construit à l'aide d'un ensemble de poutres courbes pour le carter et d'un ensemble de poutres droites pour la roue aubagée. La flexibilité de l'arbre est traduite par deux ressorts linéaires attachés au nœud central du disque. Le contact est initié par une distorsion du carter prescrite au début de la simulation et les deux structures sont ensuite laissées libres d'interagir.

Les équations du mouvement sont résolues par un algorithme d'intégration temporelle explicite (différences finies centrées) et les efforts de contact sont calculés avec des multiplicateurs de Lagrange, méthode permettant de satisfaire pleinement les conditions de non-pénétration. Le frottement est représenté par une loi de Coulomb classique et, du fait des vitesses importantes en sommets d'aubes, le glissement permanent est supposé lors des phases de contact.

Sur l'ensemble de la plage de vitesses de fonctionnement, trois types de régimes sont identifiés: (1) amortis, (2) soutenus et (3) divergents, où des mouvements de précession de l'arbre tant directes que retrogrades sont observés. Il est montré que la réponse vibratoire de la roue aubagées réside principalement sur le premier diamètre nodal de la première famille de modes, et ce, quelle que soit la vitesse de rotation ou le type de régime détecté. Le risque de défaillance résultant de ces événements de contact est mis en évidence, en particulier en présence de tournoiement direct, et le besoin d'outils prédictifs précis dans les phases préliminaires de conception du moteur est souligné.

Mots-clés

Dynamique nonlinéaire, mécanique numérique du contact, tournoiement, interaction rotor/stator, vibrations.

Laboratoire de Dynamique des Structures et Vibrations, Université McGill, 817 Sherbrooke Ouest, Pavillon McConnell, Salle 122, H3A-0C3, Montréal, Québec, Canada

* Auteur à contacter : Tél. : +1 5143985321 ; fax : +1514398 7365. Courriel : nicolas.salvat@mail.mcgill.ca 


\section{Introduction}

In modern aircraft engines, potential structural malfunctions may be induced by diverse circumstances, such as mass unbalance, blade loss, impact with external objects, casing distortion due to high thermal gradients, fluid excitations through bearings or aerodynamic loadings, among others. These incidents generally lead to complex shaft/bladed-disk/casing interactions_-caused by unilateral contact and possibly friction between rotating and stationary components, which are generally referred to as rotor/stator interactions - that may threaten the engine structural integrity as well as produce a significant loss in efficiency.

Within this framework, two types of systems must be distinguished depending on the contact interface involved in the interaction:

rotor/bearing systems: where the rotor is frequently made of a flexible shaft and rigid disks, and is supported by different types of journal-bearings, e.g. hydrodynamics or rigid bearings, liquid or gas annular seals, among others, in which case contact may occur between shaft and bearings due to large lateral vibrations;

bladed-disk/casing systems: where flexible blades and a rigid shaft are often considered and contact takes place between bladetips and casing. In this case, the deformation of the blades and the wear of the casing are the main concern.

Generally, three distinct phenomena arising from rotor/stator interactions are discussed in the literature: modal coincidence [1], rubbing [2, 3] and whirl [4].

Firstly, modal coincidence-also called travelling wave speed coincidence-is known to be a source of instability in bladeddisk/casing systems and may be visualized as a geometric matching between the vibration modes of these two flexible structures. One of the first studies to consider this phenomenon modeled the interaction as the occurrence of an impact between blade-tips and casing, and enabled the prediction of critical operational speeds [1]

Secondly, rubbing refers to two distinct phenomena depending on the system of interest. In rotor-bearing systems, it refers to direct contact between shaft and journal bearings due to large lateral displacements often caused by a mass unbalance [2], whereas in bladed-disk/casing systems, rubbing refers to the wear of the abradable coating deposited along the casing circumference and the subsequent vibratory response of the blades [3,5].

Lastly, whirl refers to precessional orbits of the shaft leading to unstable motions [6]. The rotor may undergo forward or backward whirl depending on the whirling direction with respect to the shaft rotational speed. This phenomenon has been vastly studied only for rotor/bearing systems and is related to rubbing problems once the amplitude of the whirling motion is larger than the initial rotor/bearing clearance, in which case contact occurs and may lead to dry-friction whirl [7]. Bartha showed that this type of contact can only produce backward motions by comparing a numerical model of a flexible rotor and stator with experimental results from a test rig which performed as a small turbo-compressor. He described it as "rare but potentially fatal malfunction of turbomachines" [7].

Early work made by Black [8] proved that whirling motions may lead to important changes in the vibratory behavior of the shaft once the first critical speed is passed. He considered a multidegrees of freedom (DoF) rotor and stator with damping, and dry-friction interaction at the clearance, comparing a stability analysis via polar receptances and experimental data from a test rig. Muszynska also worked on rotor/bearing stability problems, considering a symmetric rotor reduced to its first bending mode, supported by one rigid and one fluid lubricated bearings, and analyzed the phenomena known as oil whirl and oil whip [4]. The progression from whirl to whip was shown as a sub-synchronous motion at about one-half of the running speed and an asynchronous motion at the first bending natural frequency of the shaft, respectively.
Later on, a multi-mode extension of Black's model was proposed in [9] in order to study the whirl-whip transition. Good agreement was obtained between the prediction of precession frequencies and experimental values, and potentially destructive dryfriction whip was witnessed in the test rig. Similarly, a multipleDoF rotor and stator model using Timoshenko beams was built [10], combined with a component mode synthesis method to discard high frequency modes and implementing a nonlinear contact model with Coulomb friction. Good concordance between experimental data and simulation results was achieved, showing multiple whirl and whip regions.

All the studies previously cited regarding whirl involve flexible shafts with non-deformable cross-sections and the literature is rather scattered when considering whirling motions in fully flexible bladed-disks/casing systems. One of the only studies of this phenomenon was published by Padovan and Choy [11], where the transient response of a bladed Jeffcott rotor was studied. Three response configurations were detected: (1) no contact, (2) single blade contact and (3) multiple blade contact. Backward whirling motions were observed, maximizing blade displacements and stresses. A fully flexible rotor was also developed in [12] using an energetic approach in the rotating frame and considering frictionless sliding contacts. The casing was modelled as an elastic ring and the stability of the two coupled structures was addressed through eigenvalue computations, showing different divergent instabilities and mode couplings.

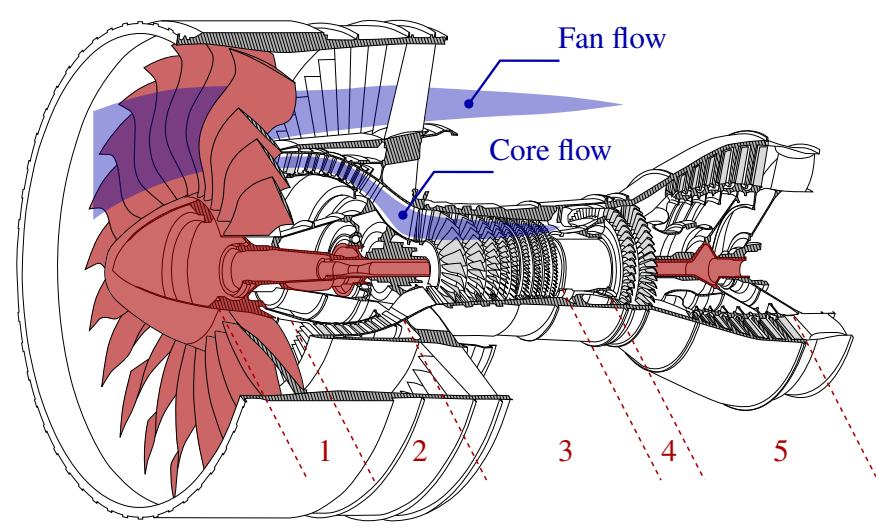

Figure 1. Two-spool aircraft engine: (1) Fan, (2) low pressure compressor, (3) high pressure compressor, (4) combustion chamber and (5) turbine stages.

In the present study, the focus is made on the shaft/bladed-disk structural coupling and the emergence of whirling motions in the fan stage of a two-spool commercial aircraft engine, pictured in Fig. 1, induced by direct blade/casing contacts due to a prescribed casing distortion. The interactions between these two flexible structures are studied for a given rotational speed range and different contact scenarios.

First, the structural 2D in-plane models of the engine stage and the simulation procedure are presented. In a second section, some of the modal characteristics of the bladed-disk are given and a convergence study is carried out to ensure the accuracy of the results. Finally, the results are presented, discussing the influence of the casing distortion as well as focusing in the detection of different types of operating regimes. Modal contributions are determined in order to characterize the type of modes involved in the interactions.

\section{Modeling strategy}

\subsection{Structural models}

The fan stage structural model used in this investigation is similar to the one presented in [13], to which the dynamics of the shaft 
are added through two linear springs connected to the center node of the disk. This structural characteristic brings an entirely new perspective to the interaction scenarios: the blade dynamics and the in-plane rigid body motions of the shaft are now coupled.

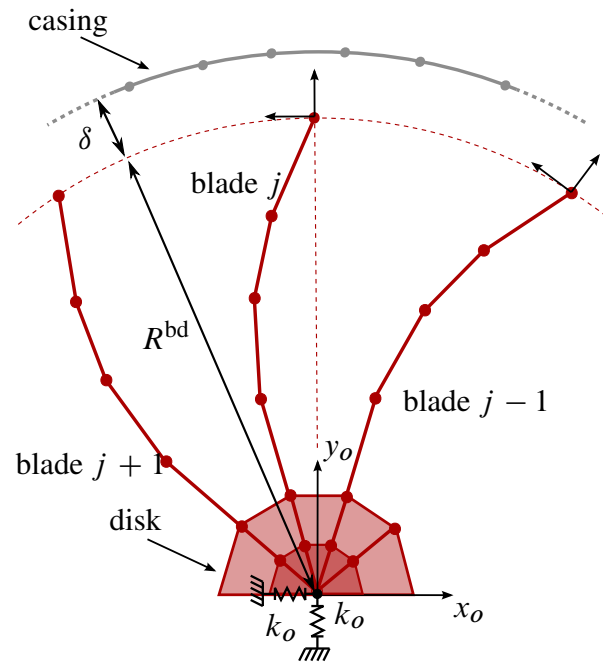

Figure 2. Schematic representation of the 2D-FEM models

The bladed-disk, illustrated in Fig. 2, is composed of an assembly of straight beams. Each element has 2 nodes with 3 DoF per node and is a combination of simple Bernoulli beams and rod elements, allowing to take into account both radial and tangential displacements. The model consists of 22 blades, with radius of $R^{b d}=0.5 \mathrm{~m}$ and 10 elements per blade, as well as a dedicated set of beams representing the disk and allowing the structural coupling between blades. The material used is steel.

By choice, the stiffness of the center node linear springs reflecting the flexibility of the shaft is defined as function of the tangential stiffness of a blade: $k_{o}=\chi k_{\text {blade }}$. The value $\chi=500$ is chosen, resulting into $k_{o}=3.4 \cdot 10^{7} \mathrm{~N} / \mathrm{m}$ and this assumption will not be discussed further in this investigation.

The casing, also depicted in Fig. 2, is built using a set of curved beams (40 elements). These elements have 2 nodes and 4 DoF per node, leading to a total of $160 \mathrm{DoF}$. The material is also steel and the casing radius is defined by the radius of the bladed-disk plus an initial clearance $\delta: R^{c}=R^{b d}+\delta$.

\subsection{Craig-Bampton model reduction}

The size of the finite element matrices involved in the time-stepping procedure does not allow for reasonable computation times since a very high number of iterations are required. Therefore, in order to decrease the number of DoF and gain computational efficiency while capturing the essential dynamic response, the bladed-disk is reduced through Craig-Bampton component mode synthesis method [14].

Physical DoF $\mathbf{x}$ are partitioned into internal DoF $\mathbf{x}_{i}$ and boundary DoF $\mathbf{x}_{b}$. The latter being kept in the reduced model for contact handling and the former being reduced to a certain number $\eta$ of modal participations $\mathbf{q}_{\mathrm{CB}}$ using expression (1),

$\mathbf{x}=\left(\begin{array}{c}\mathbf{x}_{b} \\ \mathbf{x}_{i}\end{array}\right)=\boldsymbol{\Phi}_{\mathrm{CB}}\left(\begin{array}{c}\mathbf{x}_{b} \\ \mathbf{q}_{\mathrm{CB}}\end{array}\right) \quad$ with $\quad \boldsymbol{\Phi}_{\mathrm{CB}}=\left[\begin{array}{cc}\mathbf{I} & \mathbf{0} \\ \boldsymbol{\Psi}_{s} & \boldsymbol{\Psi}_{c}\end{array}\right]$

where, $\Psi_{s}$ are static modes equal to the number of boundary DoF kept in the reduced model and $\Psi_{c}$ are $\eta$ constraint modes, controlling the accuracy of the reduction basis.

Both radial and tangential DoF of every blade-tip $\left(u_{\text {tip }}, v_{\text {tip }}\right)$ are kept in the reduced model (44 DoF), as well as the $2 \mathrm{DoF}$ from the center node. The value of the parameter $\eta=110$ is used in the following as stated in the next section, leading to $156 \mathrm{DoF}$. As for the casing, it is not reduced in this investigation since all 40 nodes are required for contact handling.

\subsection{Equations of motion and solution algorithm}

The following equations of motion govern the system:

$$
\begin{aligned}
& {\left[\begin{array}{cc}
\mathbf{M}^{\mathrm{bd}} & \mathbf{0} \\
\mathbf{0} & \mathbf{M}^{\mathrm{c}}
\end{array}\right]\left(\begin{array}{c}
\ddot{\mathbf{x}}^{\mathrm{bd}} \\
\ddot{\mathbf{x}}^{\mathrm{c}}
\end{array}\right)+\left[\begin{array}{cc}
\mathbf{D}^{\mathrm{bd}} & \mathbf{0} \\
\mathbf{0} & \mathbf{D}^{\mathrm{c}}
\end{array}\right]\left(\begin{array}{c}
\dot{\mathbf{x}}^{\mathrm{bd}} \\
\dot{\mathbf{x}}^{\mathrm{c}}
\end{array}\right)} \\
& +\left[\begin{array}{cc}
\mathbf{K}^{\mathrm{bd}} & \mathbf{0} \\
\mathbf{0} & \mathbf{K}^{\mathrm{c}}
\end{array}\right]\left(\begin{array}{c}
\mathbf{x}^{\mathrm{bd}} \\
\mathbf{x}^{\mathrm{c}}
\end{array}\right)=\left(\begin{array}{c}
\mathbf{0} \\
\mathbf{f}^{\mathrm{ext}}
\end{array}\right)+\left[\begin{array}{c}
\mathbf{B}^{\mathrm{bd}} \\
\mathbf{B}^{\mathrm{c}}
\end{array}\right] \mathbf{f}^{\mathrm{cn}}
\end{aligned}
$$

where $\mathbf{M}$ and $\mathbf{K}$ are the mass and stiffness matrices ${ }^{1}$, and $\mathbf{D}$ is the damping matrix computed from the modal domain. $\mathbf{f}^{\mathrm{ext}}$ are the external loads which are only applied to the casing and $\mathbf{f}^{\mathrm{cn}}$ are the contact forces which couple the two underlying linear systems through the contact constraints matrices $\mathbf{B}^{2}$.

The numerical procedure involved in the model can be divided into the following steps:

1. a deformation is prescribed to the casing at the beginning of the simulation along $k$ nodal diameters, in order to absorb the initial blade-tip clearance $\delta$ and initiate contact. The two structures are then left free to interact;

2. equations of motion (2) are solved through an explicit timemarching scheme (centered finite differences);

3. contact forces $\mathbf{f}^{\mathrm{cn}}$ are computed using Lagrange multipliers method, allowing to fully satisfy non-penetration conditions;

4. friction is accounted for through a Coulomb law and permanent sliding is assumed.

Based on previous works [13], the solution algorithm 1 is used to compute the time response of both structures for a given rotational speed range $\Omega \in\left[\Omega_{\mathrm{i}} ; \Omega_{\mathrm{f}}\right]$.

\section{Input:}

- geometrical and mechanical properties of casing and bladed-disk

- casing distortion: $k$, amplitude, loading duration

- reduction basis: $\eta$

- simulation parameters: speed range, time-step, simulation time $T_{\text {tot }}$,

- initial conditions

for $\Omega$ from $\Omega_{i}$ to $\Omega_{f}$ do

Initialization

for $t$ from 0 to $T_{\text {tot }}$ do prediction of displacements (centered finite differences) blade-tips to casing gap calculation if penetration detected then contact forces (Lagrange multipliers) friction forces (Coulomb law) displacements correction end end time increment

end

Output:

- bladed-disk and casing displacements $\left(\mathbf{x}^{\mathrm{bd}}, \mathbf{x}^{\mathrm{c}}\right)$

- contact forces ( $\left.\mathbf{f}^{\mathrm{cn}}\right)$

Algorithm 1: Simulation procedure

\section{Preliminary study}

In this section, some of the modal characteristics of the system of interest are introduced, going from basic cyclic-symmetry formulations to a linear modal analysis. A convergence study is also briefly presented regarding the accuracy of the time-marching algorithm as well as the Craig-Bampton modal reduction basis.

\footnotetext{
${ }^{1}$ The bladed-disk structural matrices are obtained from the finite element ones $\mathbf{M}_{\mathrm{FE}}$ and $\mathbf{K}_{\mathrm{FE}}: \mathbf{M}_{\mathrm{CB}}=\boldsymbol{\Phi}_{\mathrm{CB}}^{\mathrm{T}} \mathbf{M}_{\mathrm{FE}} \boldsymbol{\Phi}_{\mathrm{CB}}$. The subscript ${ }_{\mathrm{CB}}$ is dropped for clarity.

${ }^{2}$ Superscripts ${ }^{\text {bd }}$ and ${ }^{c}$ denote the bladed-disk and the casing, respectively.
} 


\subsection{Shaft motions in cyclically symmetric structures}

Perfectly tuned cyclically symmetric structures ${ }^{3}$, composed of $N$ identical sectors, feature modes that can be sorted by modal families and nodal diameters $k$-also called spatial harmonicsdepending on their frequency and geometrical shape:

simple harmonics: $k=0$ et $k=N / 2$ (for $N$ even), which are seen as standing waves in the rotating frame;

double harmonics:

$k \in[1 ; K] \quad$ with $\quad K= \begin{cases}\frac{N-1}{2} & \text { if } N \text { is odd } \\ \frac{N-2}{2} & \text { if } N \text { is even }\end{cases}$

composed of two orthogonal eigenmodes with the same frequency and can be combined into a unique rotating mode.

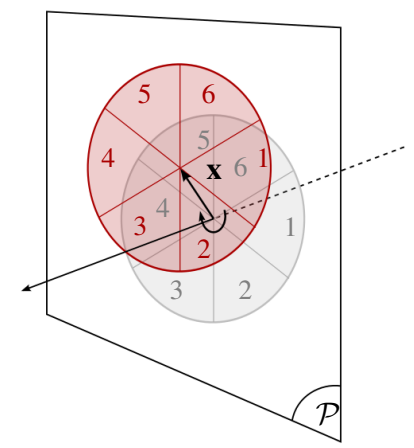

Figure 3. Example of a cyclic-symmetric structure: $N=6$

The objective of this section is to evaluate how the physical displacement of a node belonging to the axis of rotation (axis of symmetry) of a cyclically symmetric structure $\mathbf{x}$ is translated into the Fourier space $\mathbf{u}$, and determine which spatial harmonics are affected. As illustrated in Fig. 3, it is assumed that this 3-dimensional displacement can be described in a plane $\mathcal{P}$ and written in the local frame of the $n$-th sector as:

$\mathbf{x}_{n}=\left(\begin{array}{l}a \\ 0\end{array}\right)_{1}=\left(\begin{array}{c}a \cos (\alpha) \\ -a \sin (\alpha)\end{array}\right)_{2}=\cdots=\left(\begin{array}{c}a \cos ((N-1) \alpha) \\ -a \sin ((N-1) \alpha)\end{array}\right)_{N}$

where $a$ is the displacement amplitude and $\alpha=2 \pi / N$ is the intersector angular length. This equation may be written in a condensed manner as:

$\mathbf{x}_{n}=\left(\begin{array}{c}a \cos (n \alpha) \\ -a \sin (n \alpha)\end{array}\right)_{n=1 \ldots N}$

The change of variable from physical to cyclic coordinates proposed in [15] is adopted in the following.

3.1.1 Simple harmonics: $k=0$ and $k=N / 2$

$\mathbf{u}^{0}=\frac{1}{\sqrt{N}} \sum_{n=1}^{N} \mathbf{x}_{n}$

replacing $\mathbf{x}_{n}$ with Eq. (4) and using a complex exponential notation $\left(i^{2}=-1\right)$, Eq. (5) becomes:

$\mathbf{u}^{0}=\frac{1}{\sqrt{N}} \sum_{n=1}^{N}\left(\begin{array}{c}a \cos (n \alpha) \\ -a \sin (n \alpha)\end{array}\right)=\frac{1}{\sqrt{N}} \sum_{n=1}^{N}\left(\begin{array}{c}a \operatorname{Re}(\exp (\text { in } \alpha)) \\ -a \operatorname{Im}(\exp (\text { in } n))\end{array}\right)$

This sum of exponentials is a geometric sequence of reason $\exp (i \alpha)$ and may thus be written as:

$\sum_{n=1}^{N} a \exp (i n \alpha)=a \exp (i \alpha) \frac{1-\exp (i \alpha)^{N}}{1-\exp (i \alpha)}$

\footnotetext{
${ }^{3}$ Also called rotationally periodic structures.
}

since,

$\exp (i \alpha)^{N}=\exp \left(i \frac{2 \pi}{N}\right)^{N}=\exp (i 2 \pi)=1$

then,

$\sum_{n=1}^{N} a \exp ($ in $\alpha)=0+i 0 \Rightarrow \mathbf{u}^{0}=\left(\begin{array}{l}\mathbf{0} \\ \mathbf{0}\end{array}\right)$

therefore, the 0-th harmonic does not participate in the displacement of the central node. Similarly, this displacement results into a zero participation for the nodal diameter $k=N / 2$ (for $N$ even).

3.1.2 Double harmonics: $k \in[1 ; K]$

$\begin{aligned} \mathbf{u}^{k, c} & =\sqrt{\frac{2}{N}} \sum_{n=1}^{N} \mathbf{x}_{n} \cos ((n-1) k \alpha) \\ \mathbf{u}^{k, s} & =\sqrt{\frac{2}{N}} \sum_{n=1}^{N} \mathbf{x}_{n} \sin ((n-1) k \alpha)\end{aligned}$

In this case, by manipulating the sums of sines and cosines, it can be proved that:

$$
\begin{cases}k \in] 1 ; K] & \mathbf{u}^{k, c}=\mathbf{u}^{k, s}=\mathbf{0} \\ k=1 & \mathbf{u}^{k, c}=\mathbf{u}^{k, s}=a \sqrt{2 N} \cos (\alpha)\end{cases}
$$

Similar to the conclusion reached for circular plates [16], from Eq. (11) it can be stated that any displacement of a node belonging to the rotational axis of a cyclically symmetric structure solely affects the 1-nodal diameter modes. Therefore, any precessional motion of the shaft-whirl motions - may only be described as a combination of 1-nodal diameter modes for this type of structure.

\subsection{Modal analysis of the bladed-disk}

A linear modal analysis of the bladed-disk is carried out in this section to assess the influence of the flexible shaft on the structure mode shapes and eigenfrequencies. In agreement with the theoretical developments presented above, it can be seen in Fig. 4, where the mode-shapes of the first modal family have been amplified for illustrative purposes, that the center node displacement with respect to the rest position is only visible for $k=1$ (Fig. 4b).

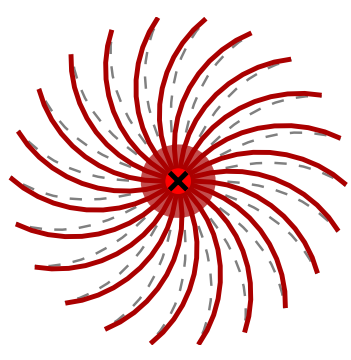

(a) $k=0$ and $f=41.66 \mathrm{~Hz}$

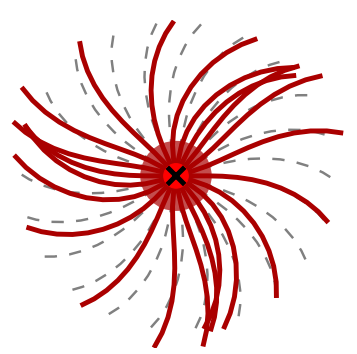

(c) $k=3$ and $f=42.02 \mathrm{~Hz}$

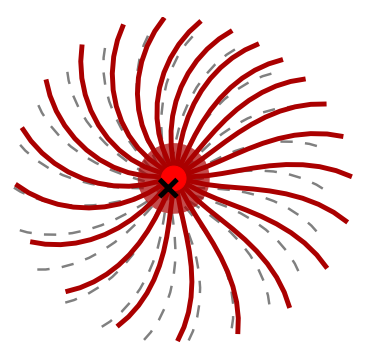

(b) $k=1$ and $f=40.84 \mathrm{~Hz}$

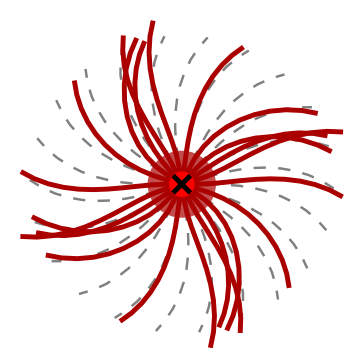

(d) $k=4$ and $f=42.01 \mathrm{~Hz}$
Figure 4. First family of free vibration modes: center node displaced [•] and rest $[\mathbf{X}]$ positions 
Furthermore, the veering diagrams presented in Fig. 5 show a comparison of the eigenfrequencies with a free and clamped center node. It can be seen in this figure how the constraints of the center node affect solely the one nodal diameter modes ( $k=1$, highlighted in blue) of each modal family.

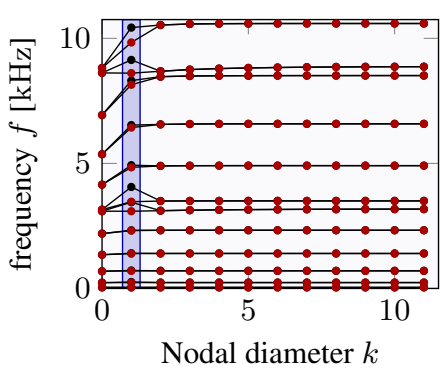

(a) 12 families of modes

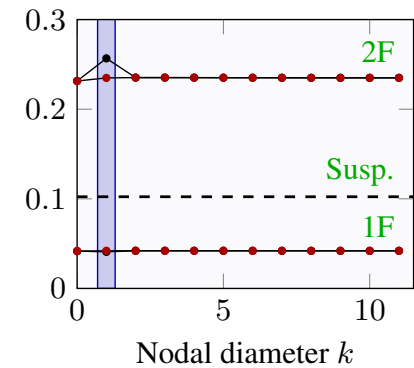

(b) 2 families of modes

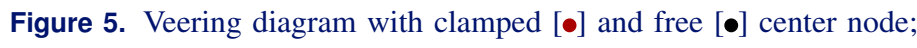
[- - - ] suspension modes

Additionally, the two DoF of the center node drive the suspension modes through the linear springs connected to it, and with the $k_{o}$ value selected, these modes appear between the first two modal families as shown in Fig. $5 \mathrm{~b}$ with a frequency $f_{o} \simeq 102.3 \mathrm{~Hz}$.

\subsection{Model convergence}

In order to ensure the accuracy of the results, a convergence study is carried out with regards to two parameters: the time-step $\Delta t$ and the reduction parameter $\eta$.

The nonlinearity of the contact force and the explicit nature of the time integration scheme make the algorithm strongly sensitive to the time-step size. Asymptotic convergence is reached for $\Delta t=10^{-6} \mathrm{~s}$, which is preserved for all simulations performed in this investigation.

Similarly, convergence is verified for different values of $\eta$. As shown in [17], the convergence is not perfectly achieved with the variation of $\eta$ in terms of the displacements but it is obtained in the types of motion observed. The value $\eta=110$ is kept for the rest of the study, giving a good approximation of the five first families of modes (up to $0.75 \%$ ) when compared to the full FE-model.

\section{Results}

Two different studies are carried out: (1) influence of the initial casing distortion, and (2) identification of operating regimes throughout the rotational speed range.

\subsection{Influence of the casing distortion}

The first study concerns the deformation imposed to the casing at the beginning of the simulation. Two different contact scenarios are proposed: $k=1$ and $k=2$ nodal diameter deformations. For each case, computations are ran using the set of parameters listed in Tab. 1 .

$\begin{aligned} \text { Parameter } & \text { Value } \\ \text { gap } & 1 \mathrm{~mm} \\ \text { number of revolutions } & 20 \\ \text { modal force } & 75 \mathrm{kN} \\ \text { friction coefficient } & \mu=0.2 \\ \text { rotational speeds } & \Omega \in[20 ; 520] \mathrm{rad} / \mathrm{s} \\ \text { casing distortion } & k=1 \text { or } k=2\end{aligned}$

Table 1. Simulation parameters - casing distortion

The results presented in Figs. 6 and 7 correspond to the frequency content of the time response of either the center node or a blade-tip tangential displacements, for each rotational speed $\Omega$. This is achieved using a Fourier Transform considering that steadystate is reached after 5 revolutions and the color code in these figures represent the vibration amplitudes, going from minimum (blue) to maximum (red).

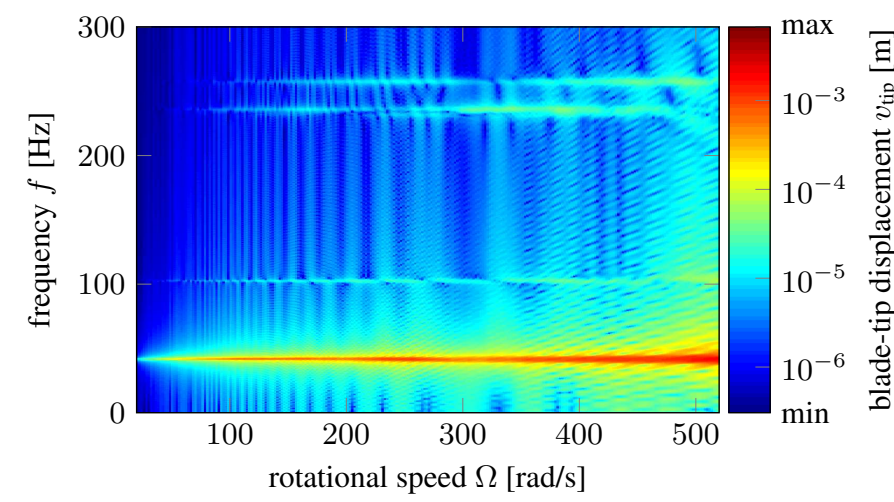

(a) blade-tip node

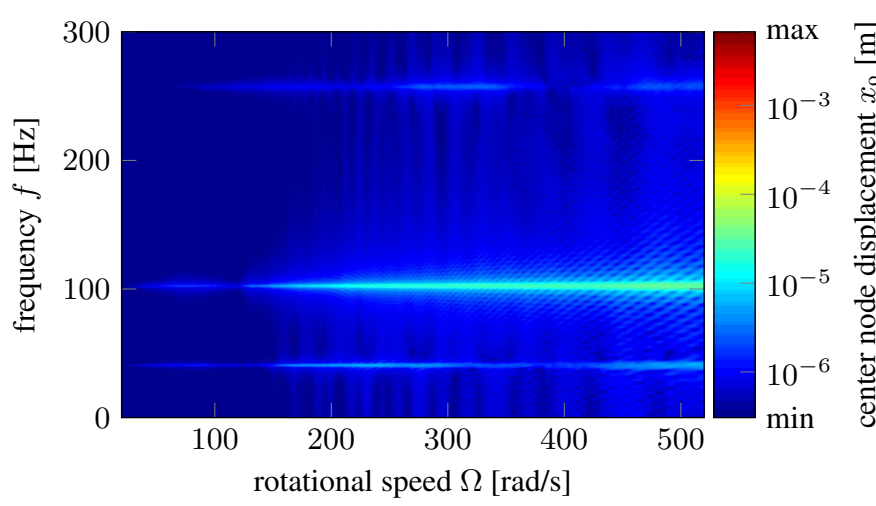

(b) center node

Figure 6. Frequency response for deformation $k=1$

As expected, it can be seen in Fig. 6 that the vibration amplitudes of the center node are far smaller than those of the blade-tips. It can also be noticed that for high rotational speeds $(\Omega>400$ $\mathrm{rad} / \mathrm{s}$ ), the Fourier Transforms are much noisier than at lower speeds, that is to say that the peaks detected are wider. This is due to the fact that steady-state is not properly reached for these speeds and the simulations should be performed with a greater number of revolutions. Yet, for the comparison purposes of this study the results obtained are satisfactory.

As shown in Fig. 6a, the blades response mainly lies in the first family of modes $(f \simeq 45 \mathrm{~Hz}$ ) where highest amplitudes are observed, but a contribution of the suspension modes $(f \simeq 105 \mathrm{~Hz})$ and the second family of modes is also noted. The split in the response of the second family of modes indicates a participation of the first nodal diameter mode of this family at $f \simeq 250 \mathrm{~Hz}$ combined with the rest at $f \simeq 240 \mathrm{~Hz}$ (c.f. Fig. 5b). This difference cannot be established for the first family of modes, since the corresponding eigenfrequencies are almost indistinguishable from one another (c.f. Fig. 5b). Furthermore, no significant peaks are detected above $f=300 \mathrm{~Hz}$.

As for the center node response, it can be noted from Fig. $6 \mathrm{~b}$ that it mainly lies on the suspension modes $(f \simeq 105 \mathrm{~Hz}$ ), with a slight contribution of the one nodal diameter of the second family of modes $(f \simeq 250 \mathrm{~Hz}$ ), as well as the first family of modes ( $f \simeq 45 \mathrm{~Hz}$ ). As expected from the modal analysis and theoretical predictions, the disappearance of the line at $f \simeq 240 \mathrm{~Hz}$ from Fig. 6a to Fig. 6b shows how the center node only participates in the 1 nodal diameter modes.

A similar trend is observed when the casing distortion is $k=2$. As depicted in Fig. 7, the blades respond mainly on the first family 


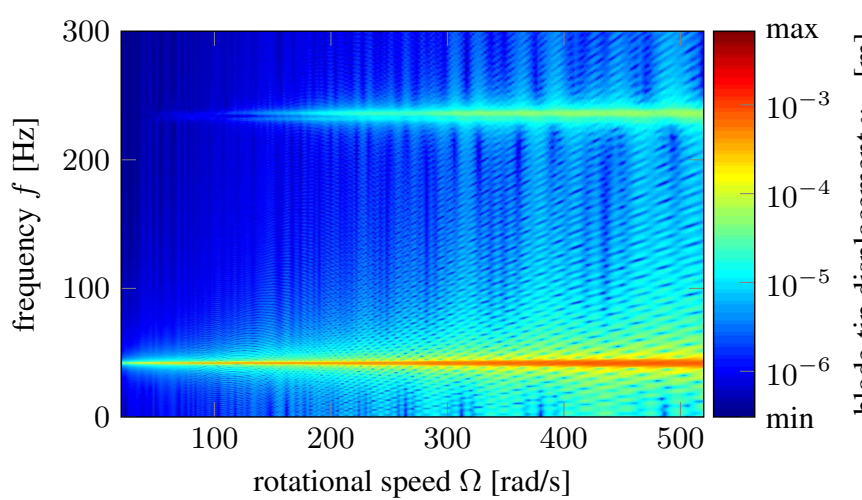

Figure 7. Frequency response for deformation $k=2$

of modes and a small contribution of the second family is also noted. The main difference between the two contact scenarios corresponds to the absence of response at $f \simeq 105 \mathrm{~Hz}$ and $f \simeq 250 \mathrm{~Hz}$ in the latter case, which is explained by the fact that the displacements of the center node are barely existent regardless of the rotational velocity considered.

Indeed, when the casing is deformed into a 1 nodal diameter shape, the eccentric displacements of the bladed-disk are favored in comparison with the case of $k=2$, where a symmetric distortion of the casing produces a symmetric response of the rotor with respect to its center. As depicted in Fig. 8, two axially opposed blades show exactly the same time response thus resulting into zero displacements of the center node.

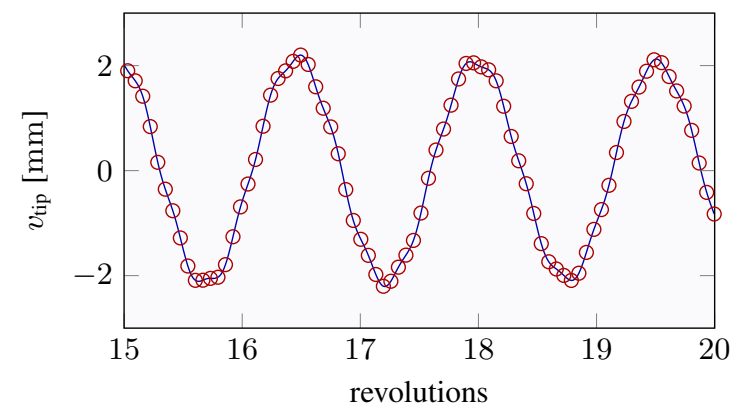

Figure 8. Displacements during last five revolutions: two axially opposed blades

In summary, a symmetric distortion of the casing does not favor the appearance of high amplitude vibrations of the shaft, thus the vibratory energy of the bladed-disk lies only on the blades. As expected from the modal analysis and theoretical developments presented above, the center node responds solely on 1 nodal diameter modes. Furthermore, in both contact configurations the contribution of the first modal family is largely predominant over the suspension and the second family of modes.

\subsection{Motion types}

In the previous sections only damped regimes were observed, i.e. regimes leading to a loss of contact after a certain number of revolution and decreasing vibration amplitudes with respect to time.

The parameters listed in Tab. 2, where the initial gap $\delta$ and friction coefficient $\mu$ are reduced, and longer computational times are used when compared to previous simulations (c.f. Tab. 1), allowed to display different types of operating regimes throughout the rotational speed range, namely:

1. damped;

2. sustained;

3. divergent.

For each type of behavior, both backward and forward traveling waves are observed on the rotor. These are studied in the static

$\begin{aligned} \text { Parameter } & \text { Value } \\ \text { simulation time } & 2.5 \mathrm{~s} \\ \text { gap } & 0.128 \mathrm{~mm} \\ \text { modal force } & 75 \mathrm{kN} \\ \text { friction coefficient } & \mu=0.1 \\ \text { rotational speeds } & \Omega \in[20 ; 520] \mathrm{rad} / \mathrm{s} \\ \text { casing distortion } & k=1\end{aligned}$

Table 2. Simulation parameters - types pf behavior

frame using the following change of variable:

$$
\left(\begin{array}{l}
X_{o} \\
Y_{o}
\end{array}\right)=\mathbf{P}\left(\begin{array}{l}
x_{o} \\
y_{o}
\end{array}\right) \quad \text { with, } \quad \mathbf{P}=\left[\begin{array}{cc}
\cos (\Omega t) & -\sin (\Omega t) \\
\sin (\Omega t) & \cos (\Omega t)
\end{array}\right]
$$

where $\left(x_{o} ; y_{o}\right)$ are the center node displacements in the rotating frame-provided by algorithm 1 - and $\left(X_{o} ; Y_{o}\right)$ are the corresponding displacements in the static frame.

The rotational speed direction is counter clockwise and the direction of the precessional motion of the shaft in the static frame is represented by a blue arrow in Figs. 9, 11 and 13. The time traces of the center note displacements are plotted in these figures, going from the transitory response to the steady-state.

Also, since the rotor response mainly lies on the first bending mode as well as the suspension modes, modal contributions $\mathbf{q}$ are computed in order to determine the type of mode involved in the interaction. This analysis is carried out only for the speeds where forward precessional motions are observed, but the conclusions are also similar in the case of backward travelling waves.

\subsubsection{Motion 1: damped}

As previously mentioned, the damped operating regime is characterized by a decrease of the vibration amplitudes in time, producing a loss of contact after a certain number of revolutions. In this case, vibration amplitudes of the transient part of the signal are much higher than those of the steady state, at which point the displacements take the shape of a convergent spiral as depicted in Fig. 9, where both backward and forward travelling waves are displayed.

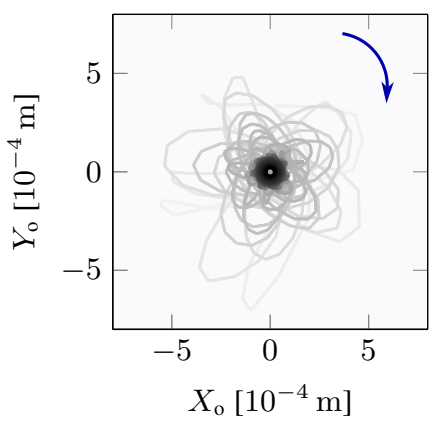

(a) $\Omega=150 \mathrm{rad} / \mathrm{s}$

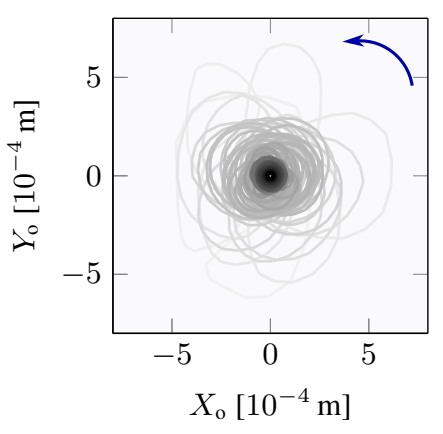

(b) $\Omega=520 \mathrm{rad} / \mathrm{s}$
Figure 9. Center node displacements: damped regime - transitory [ - ] and steady-state $[-]$ response

Modal contributions are shown in Fig. 10 for $\Omega=520 \mathrm{rad} / \mathrm{s}$. It can be seen in Fig. 10a how the 0-nodal diameter mode governs the transient part of the signal $(t<0.5 \mathrm{~s})$ and the 1-nodal diameter modes are predominant afterwards. As expected, all modal contributions $q_{k}{ }^{4}$ damp out in time.

These are stable regimes and are the less dangerous scenario, where the interaction between the two structures is limited to the transient part of the response and the lowest stresses and strains are produced.

${ }^{4} q_{k}$ denotes the $k$-th nodal diameter component of the modal contributions vector $\mathbf{q}$, with $k \in[0 ; 11]$. 

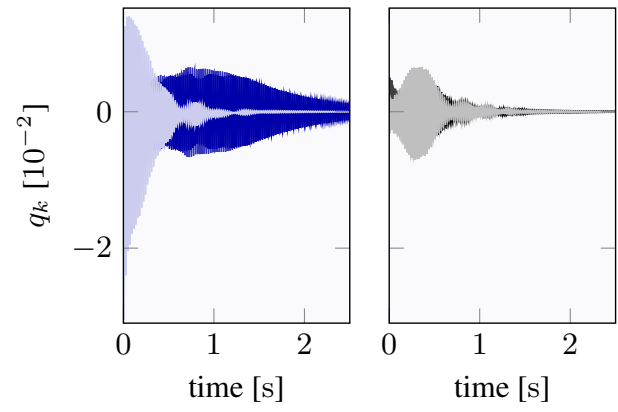

(a) $k=0[-]$ and $1[-]$

(b) $k=2$ to 11

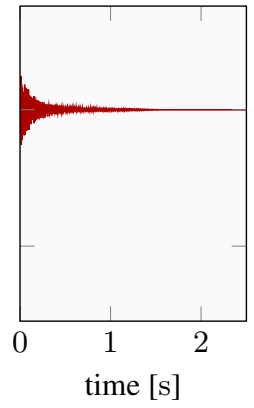

(c) susp. modes

Figure 10. Modal contributions: $\Omega=520 \mathrm{rad} / \mathrm{s}$

\subsubsection{Motion 2: sustained}

This type of movement is typically observed when the rotational speed is close to a critical speed, whether it is before or after it. As shown in Fig. 11, for both backward and forward travelling waves, when steady-state is reached, it is characterized by an orbit of almost constant amplitude with a radius of about the initial gap $\delta$. Intermittent contacts are observed and vibration levels are on the order of a tenth of a millimetre, thus much lower than in the transitory part of the response.

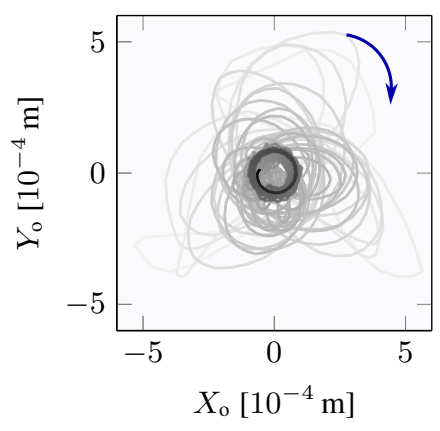

(a) $\Omega=260 \mathrm{rad} / \mathrm{s}$

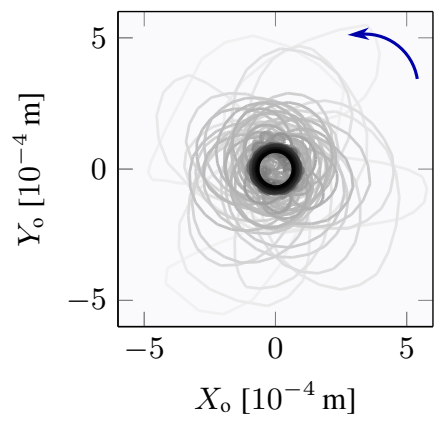

(b) $\Omega=410 \mathrm{rad} / \mathrm{s}$

Figure 11. Center node displacements: sustained regime - transitory [ $[-]$ and steady-state $[-]$ response

Like for the damped behaviors, modal contributions are computed for the forward travelling wave case $(\Omega=410 \mathrm{rad} / \mathrm{s})$ and are displayed in Fig. 12. It can be seen in this figure how the 1-nodal diameter modes stabilize after about $0.7 \mathrm{~s}$ and as all other modal contributions damp out. Similar to the damped behaviors, the 0-nodal diameter is dominant in the transient part of the signal. Even if vibration levels are low for this type of operating regime, these can lead to fatigue problems due to repetitive loading cycles on the blades. As for the casing, it is practically immune to this type of vibrations (amplitudes of the order of microns).
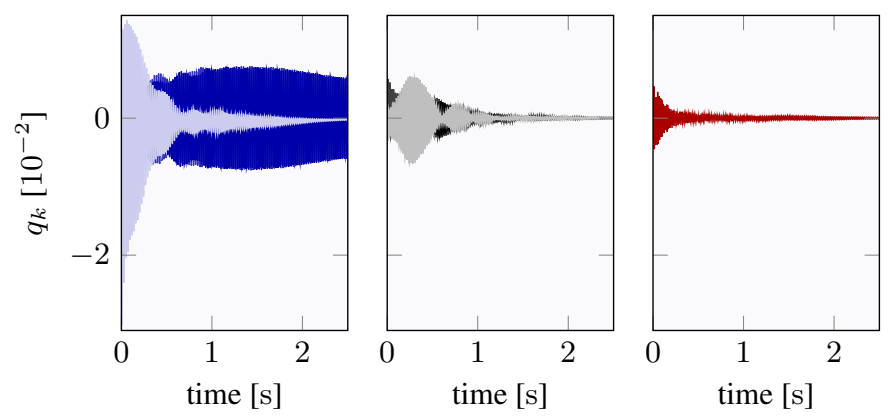

(a) $k=0[-]$ and $1[-]$

(b) $k=2$ to 11

(c) susp. modes

Figure 12. Modal contributions: $\Omega=410 \mathrm{rad} / \mathrm{s}$

\subsubsection{Motion 3: divergent}

This type of behavior is the most critical one, featuring high amplitude vibrations growing in time, i.e. divergent solutions. The linear modal coincidence prediction of critical speeds [1]:

$\omega_{k}^{c}=-\omega_{k}^{b d}+k \Omega_{k}^{c r}$

is a criterion often used in industry to determine whether potentially harmful interactions may occur within the operating range of the engine. In the present study, Eq. (13) allows for a prediction of the interaction speed of the 1-nodal diameter modes at $\Omega_{1}^{c r} \simeq 270 \mathrm{rad} / \mathrm{s}$. This prediction is effectively captured by the simulations and results are depicted in Fig. 13a, where a backward travelling wave of growing amplitude is obtained.

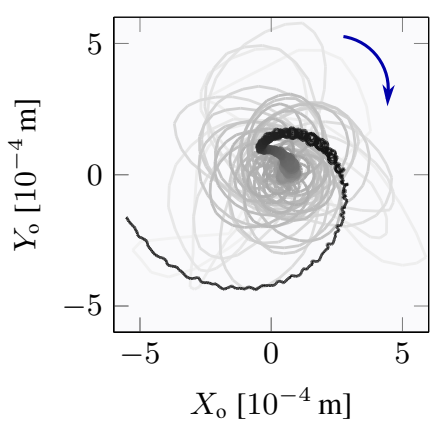

(a) $\Omega=270 \mathrm{rad} / \mathrm{s}$

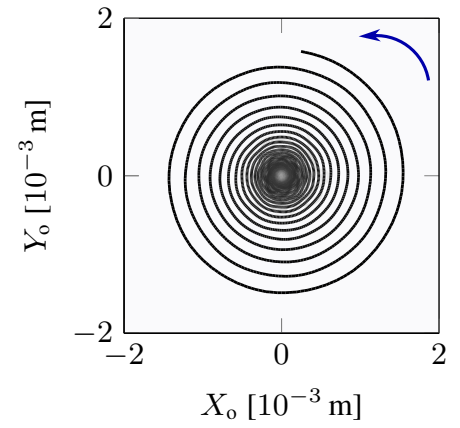

(b) $\Omega=420 \mathrm{rad} / \mathrm{s}$
Figure 13. Center node displacements: divergent regime - transitory [ - ] and divergent $[-]$ response

Another divergent motion was also identified, where the 1nodal diameter of the bladed-disk first bending mode interacts with the 9th super-harmonic in time of the 1-nodal diameter mode of the casing at $\Omega=420 \mathrm{rad} / \mathrm{s}$. This nonlinear interaction cannot be predicted by the modal coincidence criterion (13), and results in a forward precessional motion of the shaft as shown in Fig. 13b. The amplitudes are almost four times larger than in the previous case, indicating that forward whirl is potentially more dangerous than the backward analogue.

As for the modal contributions, depicted in Fig. 14, the same observations made for the two previous types of behavior are still valid. In Fig. 14a, the 1-nodal diameter modes are clearly dominant in the interaction with much higher amplitudes than any other mode. The 0-nodal diameter is also present both in the transient and steady-state parts of the response and the suspension modes mainly appear in the divergent part of the signal (Fig. 14c).

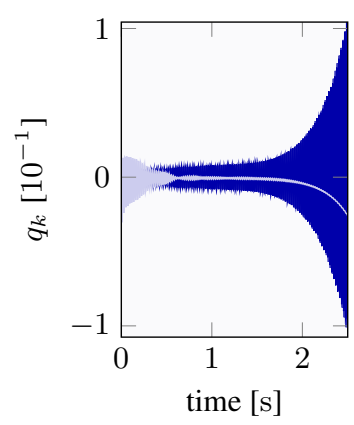

(a) $k=0[-]$ and $1[-]$

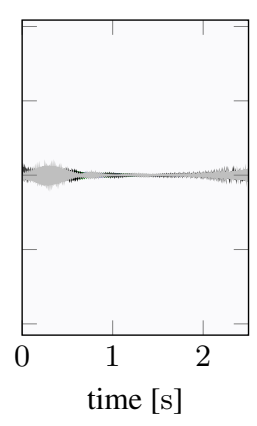

(b) $k=2$ to 11

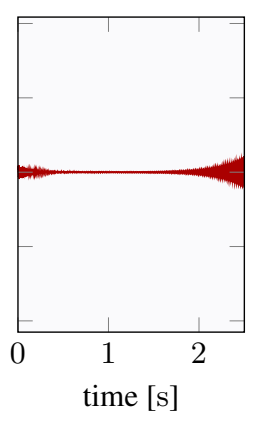

(c) susp. modes
Figure 14. Modal contributions: $\Omega=420 \mathrm{rad} / \mathrm{s}$

As was stated before, all the conclusions regarding modal contributions established in this section for forward precessional motions of the shaft are also valid for the backward counterpart. Furthermore, this set of simulations (c.f. Tab. 2) was also performed with a clamped center node (i.e. rigid shaft), resulting in 
only damped regimes and indicating that the shaft dynamics are a crucial factor in the detection of possibly dangerous interaction scenarios.

In summary, for all types of operating regimes detected, when the casing is initially distorted into a 1-nodal diameter shape favoring the eccentricity of the balded-disk, the 1-nodal diameter of its first bending mode is clearly dominant, all other modes having a negligible contribution to the global response. Therefore, all interactions involving precessional motions of the shaft are necessarily driven by this type of mode.

\section{Conclusions and perspectives}

This study focuses on the occurrence of shaft precessional motions induced by unilateral blade/casing contacts in a two-spool commercial engine fan stage. A 2D in-plane FE-model representative of a bladed-disk/casing system was built and interactions between these two flexible structures were initiated by a prescribed casing distortion. The shaft dynamics proved to have a key role in producing potentially harmful regimes, in particular in the presence of forward whirl.

Through a projection from physical to cyclic coordinates, it is revealed how 1-nodal diameter modes exclusively participate in the displacements of the shaft, thus indicating that whirling motions necessarily involve this family of modes. Different types of behavior are identified within a defined speed range, namely: (1) damped, (2) sustained, and (3) divergent, the 1-nodal diameter of the first modal family being dominant in all cases.

Finally, it is shown how a symmetric casing distortion does not favor high amplitude vibrations of the shaft. Since axially opposed blades - for an even number of sectors - display exactly the same response, this contact scenario results in a zero displacement of the central node.

These results set a basis for further investigations regarding the implementation of 3D industrial bladed-disk and bearing models. These full 3D FE-models will allow for taking into account the conical component of the whirling motions induced by the shaft bending, display more complex veering behaviors as well as to include centrifugal and gyroscopic effects, which are neglected in this preliminary study.

\section{Acknowledgement}

Thanks go to SNECMA for its technical and financial support. This work takes place in the framework of the MAIA mechanical research and technology program sponsored by CNRS, ONERA and SAFRAN Group.

\section{List of symbols}

$\boldsymbol{\Phi}_{\mathrm{CB}} \quad$ Craig-Bampton reduction matrix

$\Psi_{c} \quad$ constraint modes

$\boldsymbol{\Psi}_{s} \quad$ static modes

B contact constraints matrix

D damping matrix

K stiffness matrix

M mass matrix

P change of basis matrix

$\ddot{\mathbf{x}} \quad$ accelerations

$\dot{\mathbf{x}} \quad$ velocities

$\mathbf{f}^{\mathrm{cn}} \quad$ contact forces

f $^{\text {ext }}$ external forces

q modal contributions

$\mathbf{q}_{\mathrm{CB}} \quad$ modal contributions of constraint modes

$\mathbf{u}^{k} \quad$ cyclic coordinates of $k$-th nodal diameter

$\begin{array}{ll}\mathbf{x}_{b} & \text { boundary DoF } \\ \mathbf{x}_{i} & \text { internal DoF } \\ \alpha & \text { intersector angle } \\ \Delta t & \text { time-step } \\ \delta & \text { blade-tip clearance } \\ \eta & \text { number of constraint modes } \\ \mu & \text { friction coefficient } \\ \Omega & \text { rotational speed } \\ \Omega_{k}^{\text {cr }} & \text { critical speed of } k \text {-th nodal diameter } \\ \omega_{k} & \text { eigenfrequency of } k \text {-th nodal diameter } \\ f & \text { frequency } \\ K & \text { maximal double harmonic } \\ k & \text { nodal diameter } \\ k_{o} & \text { shaft stiffness } \\ N & \text { number of sectors } \\ q_{k} & \text { modal contribution of } k \text {-th nodal diameter } \\ R & \text { radius } \\ t & \text { time } \\ X_{o}, Y_{o} & \text { center node DoF in fixed frame } \\ x_{o}, y_{o} & \text { center node DoF in rotating frame } \\ \square^{b d} & \text { bladed-disk } \\ \square^{c} & \text { casing } \\ \square_{\mathrm{CB}} & \text { reduced matrices } \\ \square_{\mathrm{FE}} & \text { finite element matrices } \\ & \end{array}$

\section{References}

[1] P. Schmiechen. "Travelling Wave Speed Coincidence". PhD thesis. Imperial College of Science, Technology and Medicine, 1997.

[2] A. Muszynska and P. Goldman. "Chaotic responses of unbalanced rotor/bearing/stator systems with looseness or rubs". Chaos, Solitons \& Fractals 5.9 (1995), pp. 1683-1704. DOI: 10.1016/0960-0779(94)00171-L.

[3] A. Batailly, M. Legrand, A. Millecamps, and F. Garcin. "Numericalexperimental comparison in the simulation of rotor/stator interaction through blade-tip/abradable coating contact". Journal of Engineering for Gas Turbines and Power 134.8, 082504 (2012), p. 082504 . DOI: $10.1115 / 1.4006446$. OAI: hal-00746632.

[4] A. Muszynska. "Whirl and whip-Rotor/bearing stability problems". Journal of Sound and vibration 110.3 (1986), pp. 443-462. DOI: 10.1016/S0022-460X(86)80146-8.

[5] N. Salvat, A. Batailly, and M. Legrand. "Modeling of abradable coating removal in aircraft engines through delay differential equations". Journal of Engineering for Gas Turbines and Power 135.10 (2013), p. 102102. DOI: $10.1115 / 1.4024959$. OAI: hal-00879815.

[6] H.F. de Castro, K.L. Cavalca, and R. Nordmann. "Whirl and whip instabilities in rotor-bearing system considering a nonlinear force model". Journal of Sound and Vibration 317.1-2 (2008), pp. 273 293. ISSN: 0022-460X. DOI: 10.1016/j.jsv.2008.02.047.

[7] A.R. Bartha. "Dry friction backward whirl of rotors". PhD thesis. Swiss Federal Institute of Technology, Zurich, Switzerland, 2000. DOI: 10.3929/ethz-a-004130993.

[8] H.F. Black. "Interaction of a whirling rotor with a vibrating stator across a clearance annulus". ARCHIVE: Journal of Mechanical Engineering Science 1959-1982 (vols 1-23) 10.1 (1968), pp. 1-12. DOI: 10.1243/JMES_JOUR_1968_010_003_02.

[9] D.W. Childs and A. Bhattacharya. "Prediction of dry-friction whirl and whip between a rotor and a stator". Journal of vibration and acoustics 129 (2007), p. 355. DOI: $10.1115 / 1.2731412$. 
[10] J.C. Wilkes, D.W. Childs, B.J. Dyck, and S.G. Phillips. "The Numerical and Experimental Characteristics of Multimode DryFriction Whip and Whirl". Journal of Engineering for Gas Turbines and Power 132 (2010), p. 052503. DOI: $10.1115 / 1.3204658$.

[11] J. Padovan and F. K. Choy. "Nonlinear Dynamics of Rotor-BladeCasing Rub Interactions". Journal of Turbomachinery 109.4 (1987), pp. 527-534. DOI: $10.1115 / 1.3262143$

[12] N. Lesaffre, J.-J. Sinou, and F. Thouverez. "Contact analysis of a flexible bladed-rotor". European Journal of Mechanics - A/Solids 26.3 (2007), pp. 541-557. ISSN: 0997-7538.

DOI: 10.1016/j.euromechsol.2006.11.002. OAI: hal-00322887v2.

[13] M. Legrand, C. Pierre, P. Cartraud, and J.P. Lombard. "Twodimensional modeling of an aircraft engine structural bladed diskcasing modal interaction". Journal of Sound and Vibration 319.1-2 (2009), pp. 366-391. ISSN: 0022-460X.

DOI: $10.1016 /$ j.jsv.2008.06.019.

OAI: hal-00328186.
[14] R. Craig Jr. and M. Bampton. "Coupling of substructures for dynamic analysis”. AIAA journal 6.7 (1968), pp. 1313-1319.

[15] R. Bladh. "Efficient predictions of the vibratory response of mistuned bladed disks by reduced order modeling". PhD thesis. University of Michigan, 2001. OAI: tel-00358168.

[16] C-H. Kim, H. S. Cho, and H. G. Beom. "Exact solutions of in-plane natural vibration of a circular plate with outer edge restrained elastically". Journal of Sound and Vibration 331.9 (2012), pp. 2173 2189. ISSN: 0022-460X. DOI: $10.1016 / j . j s v .2011 .12 .027$.

[17] A. Batailly, M. Legrand, P. Cartraud, and C. Pierre. "Assessment of reduced models for the detection of modal interaction through rotor stator contacts". Journal of Sound and Vibration 329.26 (2010), pp. 5546-5562. ISSN: 0022-460X. DOI: $10.1016 /$ j.jsv.2010.07.018. OAI: hal-00524762. 